\title{
A responsabilidade civil do Estado frente às omissões estatais que ensejam violação à dignidade da pessoa humana*
}

Daniel Wunder Hachem

Bacharel em Direito pela Universidade Federal do Paraná. Ex-Bolsista do Programa de Educação Tutorial/Direito - UFPR (2005/2008). Ex-Presidente do Centro Acadêmico Hugo Simas (Gestão 2007/2008).

\begin{abstract}
Resumo: A Administração Pública brasileira, por força dos mandamentos constitucionais definidos na Constituição Federal de 1988, encontra-se obrigada a satisfazer os direitos fundamentais mediante a prestação de serviços públicos e à implementação de políticas públicas, de modo a proteger e promover a dignidade da pessoa humana, garantindo ao cidadão condições mínimas de existência digna. Todavia, não são raros no contexto brasileiro os casos de omissão do Poder Público, em que a Administração furta-se a implementar um serviço público inexorável à garantia do mínimo existencial, ensejando a violação da dignidade humana do cidadão. Em tais situações, é comum a apresentação da justificativa de que não havia lei específica, no plano infraconstitucional, que impusesse a prestação de determinados direitos sociais. Contudo, levando em conta a força jurídiconormativa do princípio da dignidade humana, bem como do direito fundamental ao serviço público adequado (art. 175, IV, CF), os quais permitem ao cidadão exigir da Administração as prestações positivas consideradas imprescindíveis para a pessoa e para a coletividade, não há dúvidas de que o dever da Administração Pública de garantir o mínimo existencial através da prestação de serviços públicos decorre diretamente da Constituição Federal, independendo de norma infraconstitucional que lhe imponha a obrigação de prestá-los. Conseqüentemente, se compete à Administração prestar os serviços essenciais à promoção da dignidade humana, em especial aqueles que atendam ao mínimo existencial, sempre que a sua omissão ocasionar dano ao cidadão, ver-se-á o Estado obrigado a repará-lo. Desta sorte, a omissão da Administração frente à garantia dos direitos que compõem o mínimo existencial constitui descumprimento de um dever constitucional de agir, ensejando a obrigação estatal de indenizar o cidadão que sofrer danos decorrentes da omissão administrativa.
\end{abstract}

Palavras-chave: Responsabilidade civil do Estado. Omissões estatais. Dignidade humana.

\section{Introdução}

Questiona-se cada vez mais a atuação da Administração Pública na implementação de políticas voltadas à efetivação dos direitos sociais prestacionais e dos princípios fundamentais da dignidade humana e da erradicação da pobreza, albergados na Constituição de 1988. A problemática da efetiva implementação de garantias mínimas de condições dignas de vida e de justiça social compreende um 
dos assuntos da mais alta relevância na atualidade, sendo um dos principais desafios do Estado brasileiro contemporâneo corresponder às demandas da sociedade, que clama pela realização plena do princípio da dignidade da pessoa humana. ${ }^{1}$

No entanto, a inefetividade de direitos fundamentais sociais e o conseqüente desrespeito ao princípio da dignidade humana, decorrente do fracasso do Estado no fornecimento de serviços essenciais para a promoção de uma vida digna aos cidadãos, ${ }^{2}$ rende ensejo à necessidade de se buscar mecanismos capazes de promover a reparação dos danos causados aos titulares de direitos fundamentais não efetivados pela Administração, nos casos em que a esta couber a obrigação de concretizá-los.

Nesse diapasão, o presente estudo tem por escopo identificar quais os direitos fundamentais cuja efetivação demonstra-se imprescindível à garantia de uma vida digna e qual deve ser a responsabilidade atribuída ao Estado nos casos em que a omissão da Administração Pública ocasionar violação ao princípio da dignidade humana, gerando danos aos cidadãos.

\section{0 princípio da dignidade da pessoa humana e os direitos fundamentais}

Nascido no âmbito da filosofia, o conceito da dignidade humana adquiriu juridicidade positiva e normativa como reação às práticas nazi-fascistas, configurando-se verdadeiro anticorpo jurídico contra "a praga da degradação da pessoa por outras que podem destruí-la ao chegar ao poder". ${ }^{3}$ Com o advento do Estado Social, após a Segunda Guerra Mundial, a pessoa humana passou a ocupar posição de destaque no cenário mundial, ${ }^{4}$ constituindo princípio matricial do constitucionalismo contemporâneo ${ }^{5}$ e sendo compreendida como o valor essencial que dá unidade de sentido à Constituição Federal. ${ }^{6}$

Insta ressaltar a dificuldade de se obter uma conceituação clara do que efetivamente venha a ser esta dignidade, até mesmo para se definir o seu âmbito de proteção como norma jurídica fundamental. ${ }^{7}$ Esta dificuldade justifica-se

\footnotetext{
SARLET. Direitos fundamentais sociais e proibição de retrocesso: algumas notas sobre o desafio da sobrevivência dos direitos sociais num contexto de crise. Revista Brasileira de Direito Constitucional, p. 248.

2 KRELL. Controle judicial dos serviços públicos básicos na base dos direitos fundamentais sociais. In: SARLET (Org.). A Constituição concretizada: construindo pontes com o público e o privado, p. 26.

3 ROCHA. O princípio da dignidade da pessoa humana e a exclusão social. Interesse Público, p. 29.

4 Por escapar dos limites metodológicos estabelecidos para a temática deste trabalho, não cabe aqui desenvolver uma retomada histórica acerca do surgimento da dignidade como valor intrínseco ao ser humano. Remetese o leitor, desta forma, à leitura de BARCELLOS. A eficácia jurídica dos princípios constitucionais: o princípio da dignidade da pessoa humana, p. 103-121, e BODIN DE MORAES. O conceito de dignidade humana: substrato axiológico e conteúdo normativo. In: SARLET (Org.). Constituição, direitos fundamentais e direito privado, p. 111-116.

ROCHA. Op. cit., p. 24.

6 CITTADINO. Pluralismo, direito e justiça distributiva: elementos da filosofia constitucional contemporânea, p. 13.

7 SARLET. Dignidade da pessoa humana e direitos fundamentais na Constituição Federal de 1988, p. 39.
} 
em decorrência, dentre outros fatores, da imprecisão e vagueza dos contornos deste conceito, que, nada obstante, não têm o condão de lhe esvaziar o conteúdo axiológico-normativo.

Na tentativa de alcançar uma definição minimamente objetiva, ainda que aberta, da dignidade da pessoa humana, registra Ingo Wolfgang Sarlet:

temos por dignidade da pessoa humana a qualidade intrínseca e distintiva reconhecida em cada ser humano que o faz merecedor do mesmo respeito e consideração por parte do Estado e da comunidade, implicando, neste sentido, um complexo de direitos e deveres fundamentais que asseguram a pessoa tanto contra todo e qualquer ato de cunho degradante e desumano, como venham a lhe garantir as condições existenciais mínimas para uma vida saudável, além de propiciar e promover sua participação ativa e co-responsável nos destinos da própria existência e da vida em comunhão com os demais seres humanos. ${ }^{8}$

A posição de princípio jurídico fundamental albergado na Constituição Federal empresta normatividade jurídico-positiva à dignidade da pessoa, para além do seu conteúdo ético e moral. ${ }^{9}$ A norma então passa a ser dotada, em sua plenitude, de status constitucional formal e material e, conseqüentemente, carregado de eficácia. ${ }^{10}$ Por outro lado, não se pode crer que a normatização do princípio da dignidade da pessoa humana seja suficiente para salvaguardar sua proteção. ${ }^{11}$

Compreende-se de forma majoritária na doutrina contemporânea que o princípio da dignidade da pessoa humana constitui o valor basilar dos direitos humanos e fundamentais. ${ }^{12}$ É neste contexto que se afirma que o reconhecimento e a garantia de direitos fundamentais configura uma exigência da dignidade da pessoa humana, ${ }^{13}$ pelo fato de os direitos fundamentais constituírem explicitações desta dignidade, ${ }^{14}$ de modo que em cada um deles se pode identificar um conteúdo ou alguma projeção da dignidade da pessoa. ${ }^{15}$ Não se pode confundir

8 Idem, p. 60.

9 Para uma explicação detalhada da transformação da concepção de princípios jurídicos, desde princípios gerais do direito até a configuração de princípios constitucionais, ver BONAVIDES. Curso de direito constitucional, p. 228-256.

10 SARLET. Dignidade da pessoa humana e direitos fundamentais na Constituição Federal de 1988, p. 70.

11 ROCHA. Op. cit., p. 26.

12 Tamanha é a proximidade deste princípio com o conteúdo dos direitos humanos e dos direitos fundamentais que a proteção da pessoa humana pode ser considerada como fator de aproximação entre ambas as categorias de direitos. FACHIN. Todos os nomes e um só sentido: a aproximação dos direitos humanos aos direitos fundamentais tendo em vista sua efetivação prática. Revista Brasileira de Direito Internacional, p. 57.

13 "La dignidad humana supone el valor básico (grundwert) fundamentador de los derechos humanos que tienden a explicitar y satisfacer las necesidades de la persona en la esfera moral". PÉREZ LUÑO. Derechos humanos, Estado de Derecho y Constitución, p. 318.

14 José Carlos Vieira de Andrade identifica os direitos fundamentais por seu conteúdo comum baseado no princípio da dignidade da pessoa humana, sustentando que tal princípio concretiza-se pelo reconhecimento e positivação de direitos e garantias fundamentais. ANDRADE. Os Direitos Fundamentais na Constituição Portuguesa de 1976, p. 83 e ss.

15 SARLET. Direitos fundamentais sociais e proibição de retrocesso: algumas notas sobre o desafio da sobrevivência dos direitos sociais num contexto de crise. Revista Brasileira de Direito Constitucional, p. 244. 
essa relação, entretanto, com uma suposta identidade entre os direitos fundamentais e o princípio da dignidade: esta se expressa através daqueles, compondo, de modo geral, parcela do seu conteúdo. ${ }^{16}$

Destarte, embora com diferentes graus de vinculação, a dignidade da pessoa humana, na condição de valor e princípio normativo fundamental atrai o conteúdo dos direitos fundamentais, exigindo e pressupondo o reconhecimento e proteção dos direitos fundamentais de todas as dimensões (ou gerações). ${ }^{17}$

\section{O mínimo existencial como núcleo material da dignidade da pessoa humana e as omissões estatais}

Conquanto a dignidade humana possa ser promovida em maior ou menor grau conforme a intensidade da proteção aos direitos fundamentais, é possível identificar uma linha abaixo da qual não há dignidade, que pode ser alcançada não por uma violação ativa, mas omissiva, por parte do Estado, de garantias mínimas de existência digna. Do mesmo modo como há um consenso social em relação ao desrespeito à dignidade provocado por determinadas ações, deve haver um consenso social acerca da transgressão do mesmo princípio quando a omissão do Poder Público importar uma situação de indignidade. ${ }^{18}$

Significa dizer que existe um núcleo de condições materiais que compreende a noção de dignidade humana de forma tão essencial que sua inexistência implicará indubitavelmente uma situação de indignidade, não obstante as diversas concepções de dignidade que se pode encontrar num Estado democrático e pluralista. É o que a atual doutrina passou a denominar de mínimo existencial, ${ }^{19}$ composto essencialmente por um conjunto de direitos sociais de cunho prestacional suficientes não apenas para assegurar a existência humana, mas, para além disso, uma vida com dignidade. ${ }^{20}$

Na definição de Ana Paula de Barcellos,

o mínimo existencial corresponde ao conjunto de situações materiais indispensáveis à existência humana digna; existência aí considerada não apenas como experiência física - a sobrevivência e a manutenção do corpo - mas também espiritual e intelectual, aspectos fundamentais em um Estado que se

\footnotetext{
16 Para uma posição crítica em relação ao tema ora referido, ver TAVARES. Princípio da consubstancialidade parcial dos direitos fundamentais na dignidade do homem. Revista Brasileira de Direito Constitucional, p. 233.

17 SARLET. Dignidade da pessoa humana e direitos fundamentais na Constituição Federal de 1988, p. 85.

18 BARCELLOS. Op. cit., p. 193.

19 "Há um direito às condições mínimas de existência humana digna que não pode ser objeto de intervenção do Estado e que ainda exige prestações estatais positivas". TORRES. O mínimo existencial e os direitos fundamentais. Revista Brasileira de Direito Administrativo, p. 29.

20 SARLET. Dignidade da pessoa humana e direitos fundamentais na Constituição Federal de 1988, p. 92-93.
} 
pretende, de um lado, democrático, demandando a participação dos indivíduos nas deliberações públicas, e, de outro, liberal, deixando a cargo de cada um seu próprio desenvolvimento. ${ }^{21}$

Para Ricardo Lobo Torres, o mínimo existencial carece de conteúdo específico, abrangendo quaisquer direitos imprescindíveis à existência digna, como os direitos à saúde e à alimentação, ainda que originalmente não-fundamentais. ${ }^{22}$ Segundo Ingo Sarlet, o seu conteúdo "encontra-se condicionado pelas circunstâncias históricas, geográficas, sociais, econômicas e culturais em cada lugar e momento em que estiver em causa". ${ }^{23}$

Por sua vez, Ana Paula de Barcellos propõe uma construção dogmática do mínimo existencial, a qual se traduz na identificação dos dispositivos constitucionais que afetam diretamente o núcleo material da dignidade da pessoa humana. As disposições constitucionais da Carta Magna de 1988 consistentes no mínimo existencial são reunidas sistematicamente pela autora em quatro grupos, três de natureza material e um de caráter instrumental, quais sejam, a educação fundamental, a saúde básica, a assistência aos desamparados e o acesso à Justiça. ${ }^{24}$

A saúde e a educação ensejam um primeiro momento da dignidade humana, garantindo condições iniciais para que o indivíduo possa desenvolver sua dignidade de forma autônoma. A educação configura um pressuposto para a participação do cidadão no Estado e para o exercício da cidadania, ${ }^{25}$ sendo compreendida pelo mínimo existencial somente a educação fundamental. ${ }^{26}$

As prestações relativas à saúde que fazem parte do mínimo existencial concernem apenas à saúde básica. Nos demais casos será necessário que as opções políticas pertinentes à saúde assumam a forma de lei para que se configure a existência de um direito subjetivo à saúde, e de um correspondente dever do Estado em efetivá-lo. ${ }^{27}$ Incluem-se no mínimo existencial, desta sorte, as prestações de saúde de que todos os indivíduos necessitaram (como o atendimento no parto

21 BARCELLOS. Op. cit., p. 197-198.

22 TORRES. O mínimo existencial e os direitos fundamentais. Revista Brasileira de Direito Administrativo, p. 29.

23 SARLET. Direitos fundamentais sociais e proibição de retrocesso: algumas notas sobre o desafio da sobrevivência dos direitos sociais num contexto de crise. Revista Brasileira de Direito Constitucional, p. 260.

24 BARCELLOS. Op. cit., p. 258.

25 Dentre outros, a autora sublinha os arts. 205 e 298 da CF como normas constitucionais atinentes ao elemento educacional no mínimo existencial.

${ }^{26}$ Não se está tratando aqui das condições ideais do desenvolvimento humano, mas sim das condições de vida minimamente dignas, que não requerem necessariamente altos níveis de escolaridade, embora seja desejável o seu alcance progressivo. BARCELLOS. Op. cit., p. 262.

27 Idem, p. 274. Na visão da autora, se toda e qualquer prestação de saúde pudesse ser postulada perante o Judiciário, a autoridade pública eximiria-se da obrigação de realizar as diretivas constitucionais sob a escusa de aguardar as decisões judiciais, ou até sob a desculpa de que não há recursos para tanto, em função dos gastos com o cumprimento das decisões judiciais. 
e no pós-natal), necessitam (como o saneamento básico e o atendimento preventivo em clínicas especializadas, como cardiológica), ou provavelmente irão necessitar (como o acompanhamento e controle de doenças características da terceira idade, tal qual a hipertensão) ${ }^{28}$

A assistência aos desamparados, por seu turno, é composta pelas pretensões que visam a impedir a indignidade absoluta, compreendendo a alimentação, o vestuário e o abrigo. ${ }^{29}$ Ana Paula de Barcellos menciona três possíveis formas de prestação de assistência social, apresentando, contudo, problemas intrínsecos a cada uma delas. ${ }^{30}$ De acordo com o seu entendimento, seja qual for a forma escolhida para se prestar a assistência, deve-se possibilitar aos cidadãos ao menos exigir judicialmente os bens in natura, vale dizer, "o Estado deve dispor de um estabelecimento no qual as pessoas necessitadas possam se abrigar à noite, assim como de alguma forma de programa de alimentação e vestuário para esses indivíduos". ${ }^{31}$

O acesso à justiça, por fim, é o instrumento capaz de assegurar a postulação judicial dos direitos materiais componentes do mínimo existencial. ${ }^{32}$ Sua implementação, assim como a das demais prestações referidas, encontra obstáculos, como o custo $^{33}$ e a desinformação, que impede o cidadão de ter conhecimento dos seus direitos materiais e da própria estrutura que lhe propiciaria o acesso à Justiça. ${ }^{34}$ Conseqüentemente, o Ministério Público assume importante papel nesta empreitada, por meio da propositura de ações civis públicas que defendam valores vinculados a segmentos marginalizados na sociedade. ${ }^{35}$

Sendo assim, nos casos de omissão do Poder Público, em que a Administração furta-se a implementar um serviço público inexorável à garantia do mínimo existencial, ensejando danos ao cidadão, deve ser atribuída ao Estado a responsabilidade de reparar os danos mesmo se não houver lei específica que determine a obrigação estatal de prestar o serviço? Para responder esta pergunta, impende

${ }_{28}$ Conforme exposto pela constitucionalista, desta maneira são respeitadas as quatro prioridades estabelecidas pela Constituição: "(i) a prestação do serviço de saneamento (art. 23, IX, 198, II, e 200 IV); (ii) o atendimento materno-infantil (art. 227, I); (iii) as ações de medicina preventiva (art. 198, II); e (iv) as ações de prevenção epidemiológica (art. 200, II)". Idem, p. 281.

29 A título exemplificativo, pode-se aludir ao art. 203 da CF, mencionado pela autora.

30 Entre eles o problema de tais medidas poderem vir a desestimular o trabalho.

31 Idem, p. 291.

32 Idem, p. 259-260.

33 Mais facilmente solucionável, através da assistência judiciária gratuita, da institucionalização de Defensorias Públicas e da criação de Juizados Especiais Cíveis e Criminais.

34 Idem, p. 295-300.

35 Tais como os desempregados (art. 170, VIII, da CF), os desprovidos de teto (art. 23, IX, da CF), os rurículas sem terra (art. 186 da CF), entre outros. MANCUSO. A ação civil pública como instrumento de controle judicial das chamadas políticas públicas. In: MILARÉ (Coord.). Ação civil pública, p. 794. 
analisarmos a teoria da responsabilidade extracontratual do Estado aplicável no Direito Administrativo brasileiro.

\section{A responsabilidade extracontratual do Estado nos casos de omissão da Administração Pública}

Havendo omissão administrativa na prestação de atividades essenciais à realização dos direitos fundamentais e configurada a existência de dano sofrido pelo cidadão, seja pela falta de acesso ao serviço público adequado e prestado de forma eficiente pela Administração, seja pela inexistência de políticas públicas destinadas à promoção de tais direitos, exsurge a questão relativa ao dever do Estado em reparar o dano.

A responsabilidade civil extracontratual do Estado decorre da necessidade de uma melhor proteção aos direitos do cidadão, frente às lesões ocasionadas pelo Estado. ${ }^{36}$ No Estado brasileiro a responsabilidade civil do Estado encontra-se prevista no art. $37, \S 6^{\circ}$ da CF, podendo derivar de "atos jurídicos, de atos ilícitos, de comportamentos materiais ou de omissão do Poder Público". ${ }^{37}$ Consoante Romeu Felipe Bacellar Filho, o instituto deita raízes no princípio republicano e no Estado Democrático de Direito (art. $1^{\circ}$, caput da CF), uma vez que a juridicidade no exercício do poder reclama que o Estado seja responsabilizado por seus atos que lesionem direitos alheios. ${ }^{38}$

Ocorrendo prejuízos ao cidadão por conta de comportamento comissivo ou omissivo do Poder Público, nasce o dever do Estado de repará-los. No que diz respeito à obrigação estatal de indenizar os particulares nos casos de danos decorrentes de omissão da Administração, a doutrina atual não diverge, entendendo de forma uníssona pela obrigação estatal de reparar os danos causados a particulares tanto por ações quanto por omissões administrativas. ${ }^{39}$ São, contudo, as peculiaridades da situação acima exposta que demandam um exame mais detido, para se concluir se a falta de serviços públicos que garantam a efetivação do mínimo existencial é suficiente para imputar ao Estado o dever de indenizar o cidadão, ainda que não haja norma infraconstitucional expressa e específica impondo uma obrigação ao Estado para agir de determinada forma.

36 ZANCANER. Da responsabilidade extracontratual da Administração Pública, p. 21.

37 DI PIETRO. Direito administrativo, p. 617.

38 BACELLAR FILHO. Responsabilidade civil da Administração Pública: aspectos relevantes: a Constituição Federal de 1988: a questão da omissão: uma visão a partir da doutrina e da jurisprudência brasileiras. In: FREITAS (Org.). Responsabilidade civil do Estado, p. 297.

39 BACELLAR FILHO. Direito administrativo, p. 217; BANDEIRA DE MELLO. Curso de direito administrativo, p. 977; DI PIETRO. Op. cit., p. 618; FIGUEIREDO. Curso de direito administrativo, p. 264; MOREIRA. Processo administrativo: princípios constitucionais e a Lei 9.784/99, p. 106. 
Consoante Marçal Justen Filho, os elementos caracterizadores da responsabilidade civil extracontratual do Estado por omissão são: “(a) dano material ou moral sofrido por alguém, (b) uma ação ou omissão antijurídica imputável ao Estado, (c) um nexo de causalidade entre o dano e a ação ou omissão estatal". ${ }^{40}$

No que diz respeito ao dano, parece não haver grandes polêmicas, sem embargo da necessidade de estarem presentes determinadas características, a saber: a especialidade (distinção no tocante aos casos de atuação geral da Administração, devendo ser específico em relação a determinada pessoa), a anormalidade (superação de limites razoáveis) e a ofensa a direito ou interesse juridicamente protegido. ${ }^{41} \mathrm{O}$ mesmo se diga em relação ao nexo de causalidade, que deve constituir um elo de ligação entre a ação ou omissão da Administração e o dano sofrido.

A grande controvérsia situa-se na antijuridicidade da omissão. Segundo Marçal Justen Filho, só se poderá imputar responsabilidade a uma omissão do Estado quando esta configurar infração a um dever específico de diligência da Administração, no exercício de suas competências próprias. ${ }^{42}$ A questão de fundo que se coloca é, portanto, a seguinte: em que medida a Administração Pública brasileira está submetida a um dever específico de prestar serviços públicos e implementar políticas públicas aptas a satisfazer os direitos fundamentais, decorrente diretamente da Constituição Federal, independentemente de qualquer lei que assim determine?

Cumpre, portanto, investigar se a falta de serviços públicos que garantam a efetivação do mínimo existencial é suficiente para imputar ao Estado o dever de indenizar nas hipóteses de dano a titulares de direitos fundamentais não efetivados, ainda que não haja norma infraconstitucional expressa e específica determinando uma obrigação do Estado em prestar o serviço.

Consoante Romeu Felipe Bacellar Filho, o direito fundamental ao serviço público adequado ${ }^{43}$ tem sido reconhecido pela doutrina administrativa brasileira, ${ }^{44}$ com fundamento no art. 175, inciso IV da Constituição Federal. Este direito permite ao cidadão exigir da Administração as prestações positivas consideradas necessárias, "imprescindíveis para a pessoa e para a coletividade". ${ }^{45}$ Nesta toada, o jurista

\footnotetext{
40 JUSTEN FILHO. CUrso de direito administrativo, p. 951.

41 BACELLAR FILHO. Responsabilidade civil da Administração Pública: aspectos relevantes: a Constituição Federal de 1988: a questão da omissão: uma visão a partir da doutrina e da jurisprudência brasileiras. In: FREITAS, Juarez (org). Responsabilidade civil do Estado. São Paulo: Malheiros, 2006. p. 327.

42 JUSTEN FILHO, Marçal. Op. cit., p. 955.

43 BACELLAR FILHO. Direito administrativo, p. 174.

44 Nesse sentido, DALLARI. Direito ao uso dos serviços públicos. Revista Trimestral de Direito Público, p. 215 e ROCHA. Estudos sobre concessão e permissão de serviço público no direito brasileiro, p. 32.

45 Id., Ibid.
} 
supracitado acentua a instrumentalidade do serviço público em relação aos direitos fundamentais, considerando-o como "meio que, ao possibilitar o exercício de direitos fundamentais, encontra seu fim na realização prática do valor máximo do sistema jurídico brasileiro: a dignidade da pessoa humana" ${ }^{46}$

Adotando-se a posição de Romeu Felipe Bacellar Filho quanto à instrumentalidade dos serviços públicos em face dos direitos fundamentais, com o intuito de realizar a dignidade da pessoa humana, não há dúvidas de que o dever da Administração Pública de garantir o mínimo existencial através da prestação de serviços públicos decorre diretamente da Constituição Federal, independendo de norma infraconstitucional que lhe imponha a obrigação de prestá-los.

Conseqüentemente, se compete à Administração prestar os serviços essenciais à promoção da dignidade humana, em especial aqueles que atendam ao mínimo existencial (saúde básica, educação fundamental, assistência aos desamparados e acesso à justiça), sempre que a sua omissão ocasionar dano ao cidadão, ver-se-á o Estado obrigado a repará-lo. Isso porque, no Estado Constitucional contemporâneo, vige o princípio da constitucionalidade, que erige a Constituição como Lei Maior, cujas normas devem nortear todo o ordenamento jurídico. ${ }^{47}$ No que diz respeito ao princípio da constitucionalidade, deve-se destacar que "não somente por ação se viola o texto constitucional, mas também por omissão". ${ }^{48}$ Desta sorte, a omissão da Administração frente à garantia dos direitos que compõem o mínimo existencial constitui descumprimento de um dever constitucional de agir, ensejando a obrigação estatal de indenizar o cidadão que sofrer danos decorrentes da omissão administrativa.

\section{Conclusão: elementos necessários à configuração da responsabilidade civil do Estado frente à violação da dignidade humana}

Uma vez constatado que é dever do Estado reparar os danos ocasionados pela não-prestação de serviços pela Administração que impossibilite a efetivação de direitos que compõem o mínimo existencial, impende analisar quais os elementos que devem estar presentes para configurar a responsabilidade civil do Estado.

$\mathrm{O}$ art. $37, \S 6^{\circ}$ da Constituição Federal dispõe que "As pessoas jurídicas de direito público e as de direito privado prestadoras de serviços públicos responderão

\footnotetext{
46 Id., Ibid.

47 FERRARI. Normas constitucionais programáticas: normatividade, operatovidade e efetividade, p. 31.

48 SOUZA. Normas constitucionais não-regulamentadas: instrumentos processuais, p. 44.
} 
pelos danos que seus agentes, nessa qualidade, causarem a terceiros, assegurado o direito de regresso contra o responsável nos casos de dolo ou culpa”. Assim, a regra geral compreendida pela doutrina é a teoria da responsabilidade objetiva do Estado, partindo-se da idéia de que, se a Carta Magna só exige dolo ou culpa para direito de regresso contra o funcionário, significa que tal exigência não se aplica também às pessoas jurídicas. ${ }^{49}$

Para a configuração da responsabilidade objetiva do Estado, faz-se então necessário: (i) que se trate de pessoa jurídica de direito público ou de direito privado prestadora de serviços públicos; (ii) que tais entidades prestem serviços públicos; (iii) que haja um dano causado a terceiros por conta da prestação de serviços públicos, configurando-se um nexo de causalidade entre a prestação dos serviços e a ocorrência do dano; ${ }^{50}$ (iv) que o dano seja indenizável, isto é, que ofenda um bem, interesse, ou direito legitimamente protegido; ${ }^{51}$ (v) que o dano seja causado por agente das referidas pessoas jurídicas, agindo nessa qualidade.

Contudo, na situação sob exame, surge uma divergência doutrinária quanto à aplicação da teoria da responsabilidade objetiva do Estado. Quando o dano causado pela Administração decorre de omissão estatal, determinados autores entendem que a teoria aplicável é a da responsabilidade subjetiva, exigindo-se a comprovação de culpa ou dolo, ${ }^{52}$ ao passo que outros consideram aplicável a teoria da responsabilidade objetiva, subordinando o dever de reparar o dano à demonstração do nexo causal entre o dano sofrido pelo particular e a conduta omissiva da Administração. ${ }^{53}$

De toda sorte, seja aplicando-se a teoria da responsabilidade subjetiva, seja aplicando-se a teoria da responsabilidade objetiva, para que o Estado seja obrigado a indenizar o particular é imprescindível que se prove a ocorrência de um dano concreto, derivado da não-prestação de um serviço essencial à satisfação do mínimo existencial, bem como o nexo causal entre o dano e a não-prestação do serviço. ${ }^{54}$

Abstract: The Brazilian Public Administration, due to the constitutional commandments defined in the Federal Constitution of 1988, is obligated

\footnotetext{
49 DI PIETRO. Op. cit., p. 623.

50 DI PIETRO. Op. cit., p. 624.

51 BACELLAR FILHO. Direito administrativo, p. 218.

52 Assim entendem, entre outros, MELLO. Princípios gerais de direito administrativo, p. 482-497; BANDEIRA DE MELLO. Curso de direito administrativo, p. 996-1001; DI PIETRO. Op. cit., p. 625; MOREIRA NETO. Curso de direito administrativo, p. 580.

53 É o posicionamento de autores como BACELLAR FILHO. Direito administrativo e o novo Código Civil, p. 236; MOREIRA. Op. cit., p. 112-118; ROCHA. Princípios constitucionais dos servidores públicos, p. 381; MEDAUAR. Direito administrativo moderno, p. 430; ZANCANER. Op. cit., p. 62.

54 BACELLAR FILHO. Direito administrativo, p. 215.
} 
to satisfy the fundamental rights through the public services and public politics, in order to protect and to promote the human dignity, guaranteeing to the citizen minimum conditions of deign being. However, the cases of omission of the Public Power are not rare in the Brazilian context, in that the Administration avoids to implement a public service which is indispensable to the warranty of the minimum existential, provoking the violation of the citizen's human dignity. In such situations, it is common the presentation of the justification that there was no specific law determining the installment of certain social rights. Nevertheless, considering the juridicalnormative force of the human dignity principle and the fundamental right to the appropriate public service (art. 175, IV, CF), which allows the citizen to demand the positive installments of the Administration considered indispensable for the person and for the collectivity, there are no doubts that the duty of the Public Administration of guaranteeing the minimum existential through the public services elapses directly from the Federal Constitution, and it does not depend on laws that impose the obligation of rendering them. Consequently, if it competes to the Administration to render the essential services to the promotion of the human dignity, especially those that meet the minimum existential, whenever its omission causes damage to the citizen, the State will be forced to repair it. Therefore, the omission of the Administration front to the warranty of the rights that compose the minimum existential constitutes noncompliance of a constitutional duty of acting, engendering the State's obligation of compensating the citizen that suffers damages caused by the administrative omission.

Keywords: Civil responsibility of the state. State omissions. Human dignity.

\section{Referências}

ANDRADE, José Carlos Vieira. Os Direitos Fundamentais na Constituição Portuguesa de 1976. Coimbra: Almedina, 1987.

BACELlAR FILHO, Romeu Felipe. Direito administrativo e o Novo Código Civil. Belo Horizonte: Forum, 2007.

BACELlAR FILHO, Romeu Felipe. Direito administrativo. 3. ed. São Paulo: Saraiva, 2007.

BACELLAR FILHO, Romeu Felipe. Responsabilidade civil da Administração Pública: aspectos relevantes: a Constituição Federal de 1988: a questão da omissão: uma visão a partir da doutrina e da jurisprudência brasileiras. In: FREITAS, Juarez (Org.). Responsabilidade civil do Estado. São Paulo: Malheiros, 2006.

BARCELLOS, Ana Paula de. A eficácia jurídica dos princípios constitucionais: o princípio da dignidade da pessoa humana. Rio de Janeiro: Renovar, 2002.

BODIN DE MORAES, Maria Celina. O conceito de dignidade humana: substrato axiológico e conteúdo normativo. In: SARLET, Ingo Wolfgang (Org.). Constituição, direitos fundamentais e direito privado. Porto Alegre: Livraria do Advogado, 2003.

BONAVIDES, Paulo. Curso de direito constitucional. 5. ed. São Paulo: Malheiros, 1994.

CITTADINO, Gisele. Pluralismo, direito e justiça distributiva: elementos da filosofia constitucional contemporânea. Rio de Janeiro: Lumen Juris, 2004. 
DALLARI, Adílson de Abreu. Direito ao uso dos serviços públicos. Revista Trimestral de Direito Público, São Paulo, n. 13, 1996.

DI PIETRO, Maria Sylvia Zanella. Direito administrativo. 19. ed. São Paulo: Atlas, 2006.

FACHIN, Melina Girardi. Todos os nomes e um só sentido: a aproximação dos direitos humanos aos direitos fundamentais tendo em vista sua efetivação prática. Revista Brasileira de Direito Internacional, v. 3, 2006.

FERRARI, Regina Maria Macedo Nery. Normas constitucionais programáticas: normatividade, operatovidade e efetividade. São Paulo: Revista dos Tribunais, 2001.

FIGUEIREDO, Lúcia Valle. Curso de direito administrativo. 6. ed. São Paulo: Malheiros, 2003.

FREITAS, Juarez (Org.). Responsabilidade civil do Estado. São Paulo: Malheiros, 2006.

JUSTEN FILHO, Marçal. Curso de direito administrativo. 3. ed. São Paulo: Saraiva, 2008.

KRELL, Andreas J. Controle judicial dos serviços públicos básicos na base dos direitos fundamentais sociais. In: SARLET, Ingo Wolfgang (Org.). A Constituição concretizada: construindo pontes com o público e o privado. Porto Alegre: Livraria do Advogado, 2000.

MANCUSO, Rodolfo de Camargo. A ação civil pública como instrumento de controle judicial das chamadas políticas públicas. In: MILARÉ, Edis (Coord.). Ação civil pública. São Paulo: Revista dos Tribunais, 2001.

MEDAUAR, Odete. Direito administrativo moderno. 5. ed. São Paulo: Revista dos Tribunais, 2001.

MELLO, Celso Antônio Bandeira de. Curso de direito administrativo. 25. ed. São Paulo: Malheiros, 2008.

MELlo, Oswaldo Aranha Bandeira de. Princípios gerais de direito administrativo. Rio de Janeiro: Forense, 1979. v. 2.

MILARÉ, Edis (Coord.). Ação civil pública. São Paulo: Revista dos Tribunais, 2001.

MOREIRA NETO, Diogo de Figueiredo. Curso de direito administrativo. 12. ed. Rio de Janeiro: Forense, 2001.

MOREIRA, Egon Bockmann. Processo administrativo: princípios constitucionais e a Lei 9.784/99. São Paulo: Malheiros, 2000.

PÉREZ LUÑO, Antonio E. Derechos humanos, Estado de Derecho y Constitución. 5. ed. Madrid: Tecnos, 1995.

ROCHA, Cármen Lúcia Antunes. Estudos sobre concessão e permissão de serviço público no direito brasileiro. São Paulo: Saraiva, 1996.

ROCHA, Cármen Lúcia Antunes. O princípio da dignidade da pessoa humana e a exclusão social. Interesse Público, n. 4, 1999.

ROCHA, Cármen Lúcia Antunes. Princípios constitucionais dos servidores públicos. Belo Horizonte: Del Rey, 1994.

SARLET, Ingo Wolfgang (Org.). A constituição concretizada: construindo pontes com o público e o privado. Porto Alegre: Livraria do Advogado, 2000. 
SARLET, Ingo Wolfgang (Org.). Constituição, direitos fundamentais e direito privado. Porto Alegre: Livraria do Advogado, 2003.

SARLET, Ingo Wolfgang. Dignidade da pessoa humana e direitos fundamentais na Constituição Federal de 1988. 4. ed. Porto Alegre: Livraria do Advogado, 2006.

SARLET, Ingo Wolfgang. Direitos fundamentais sociais e proibição de retrocesso: algumas notas sobre o desafio da sobrevivência dos direitos sociais num contexto de crise. Revista Brasileira de Direito Constitucional, São Paulo, v. 4, jul./dez. 2004.

SOUZA, Luciane Moessa de. Normas constitucionais não-regulamentadas: instrumentos processuais. São Paulo: Revista dos Tribunais, 2004.

TAVARES, André Ramos. Princípio da consubstancialidade parcial dos direitos fundamentais na dignidade do homem. Revista Brasileira de Direito Constitucional, São Paulo, v. 4, jul./dez. 2004.

TORRES, Ricardo Lobo. O mínimo existencial e os direitos fundamentais. Revista Brasileira de Direito Administrativo, Rio de Janeiro, v. 177, 1989.

ZANCANER, Weida. Da responsabilidade extracontratual da Administração Pública. São Paulo: Revista dos Tribunais, 1981.

Informação bibliográfica deste texto, conforme a NBR 6023:2002 da Associação Brasileira de Normas Técnicas (ABNT):

HACHEM, Daniel Wunder. A responsabilidade civil do Estado frente às omissões estatais que ensejam violação à dignidade da pessoa humana. A\&C-Revista de Direito Administrativo e Constitucional, Belo Horizonte, ano 8, n. 34, p. 59-71, out./dez. 2008. 